\title{
Synthesis of novel BTPhen-functionalized silica-coated magnetic nanoparticles for separating trivalent actinides and lanthanides
}

Article

Accepted Version

Afsar, A., Cowell, J., Distler, P., Harwood, L. M., John, J. and Westwood, J. (2017) Synthesis of novel BTPhen-functionalized silica-coated magnetic nanoparticles for separating trivalent actinides and lanthanides. Synlett, 28 (20). pp. 2795-2799. ISSN 0936-5214 doi: https://doi.org/10.1055/s-0036-1590865 Available at https://centaur.reading.ac.uk/71174/

It is advisable to refer to the publisher's version if you intend to cite from the work. See Guidance on citing.

To link to this article DOI: http://dx.doi.org/10.1055/s-0036-1590865

Publisher: Thieme

All outputs in CentAUR are protected by Intellectual Property Rights law, including copyright law. Copyright and IPR is retained by the creators or other copyright holders. Terms and conditions for use of this material are defined in the End User Agreement. 


\section{CentAUR}

Central Archive at the University of Reading

Reading's research outputs online 


\section{Synthesis of Novel BTPhen-functionalized Silica-coated Magnetic Nanoparticles for Separating Trivalent Actinides and Lanthanides}

\author{
Ashfaq Afsara \\ Joseph Cowella \\ Petr Distlerb \\ Laurence M. Harwood*a \\ Jan John ${ }^{b}$ \\ James Westwood \\ ${ }^{a}$ Chemical Sciences, University of Reading, Whiteknights, \\ Reading Berkshire RG6 6AD, UK. \\ I.m.harwood@reading.ac.uk \\ ${ }^{b}$ Department of Nuclear Chemistry, Czech Technical University \\ in Prague, Břehová 7, 11519 Prague 1, Czech Republic. \\ jan.john@fjfi.cvut.cz \\ Dedicated to Professor Victor Snieckus on the occasion \\ of his $80^{\text {th }}$ birthday
}

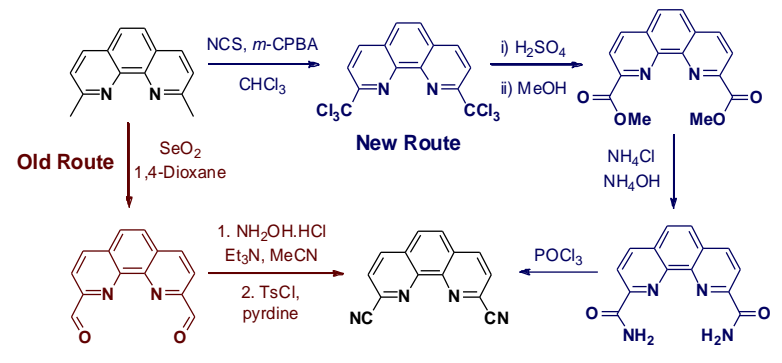

Abstract BTPhen [bis-(1,2,4-triazin-3-yl)-1,10-phenanthroline] functionalized magnetic nanoparticles (MNPs), which selectively extract Am(III) over Eu(III) from $0.1 \mathrm{M} \mathrm{HNO}_{3}$ with fast kinetics and a separation factor of 30 have been synthesized. These MNPs also show a small but significant selectivity for $\mathrm{Am}$ (III) over $\mathrm{Cm}$ (III) with a separation factor of around 3 in $0.1 \mathrm{M} \mathrm{HNO}_{3}$. We report also the synthesis of these BTPhen and related ligands via an improved synthetic route by-passing the problematic benzylic oxidation with stoichiometric $\mathrm{SeO}_{2}$.

Key words Spent nuclear fuel, BTPhen ligand, magnetic nanoparticles, solid phase extraction, benzylic halogenation.

Spent nuclear fuel produced by current nuclear reactors is comprised mainly of uranium, plutonium, the lanthanides (98.5\%) and approximately $0.1 \mathrm{wt} \%$ of the minor actinides [Am(III), Cm(III) and $\mathrm{Np}(\mathrm{III})]^{1,2}$ Despite only accounting for approximately $1 \mathrm{wt} \%$ of spent fuel, $\mathrm{Pu}$ and the minor actinides are the main contributors to the long-term radiotoxicity $\left(t_{1 / 2}=\right.$ $10^{3}$ to $10^{6}$ years) and heat load in spent nuclear fuel.3,4 Currently, uranium and plutonium are separated industrially by solvent extraction process (PUREX) and recycled after their conversion to produce new fuel.5,6 One proposed approach currently being studied is the partitioning and transmutation of minor actinides to short-lived radionuclides or stable nonradioactive elements using high-energy neutrons in dedicated ADS (accelerator driven systems) transmuters or fast neutrons in a Generation IV reactor. However, to achieve this, selective extraction of minor actinides from neutron absorbing poisons (lanthanides) is required.7-10

Separation of trivalent actinides from trivalent lanthanides is a challenging goal as the physicochemical properties of the two groups of elements are very similar. ${ }^{11}$ This renders their chemical separation a challenging task, particularly given the high radioactivity of the waste necessitating the need for remote handling. Fortunately, previous studies have shown that separation of the minor actinides from lanthanides can be achieved by the SANEX solvent extraction process (Selective ActiNide EXtraction) using soft $\mathrm{N}$-donor ligands containing the 1,2,4-triazine moiety (Figure 1).12-17 It has been postulated that one of the major contributors to this selectivity is the more radially extended nature of the $5 f$-actinide orbitals versus the $4 f$ lanthanide orbitals. ${ }^{18}$ Consequently, it is believed that the metal- ligand bonding interaction in actinide complexes is more covalent in nature than in lanthanide complexes. ${ }^{2,18} \mathrm{CyMe}_{4}$ BTBP $\mathbf{1}$ is the current European reference ligand capable of performing such extractions and a laboratory demonstration has been successfully carried out on post-PUREX raffinate. ${ }^{19}$ The more pre-organized 2,9-bis(1,2,4-triazin-3-yl)-1,10phenanthroline (BTPhen) ligand 2 was recently reported as a highly efficient and selective minor actinide extraction agent with greatly improved properties compared to $1 .^{20,21}$

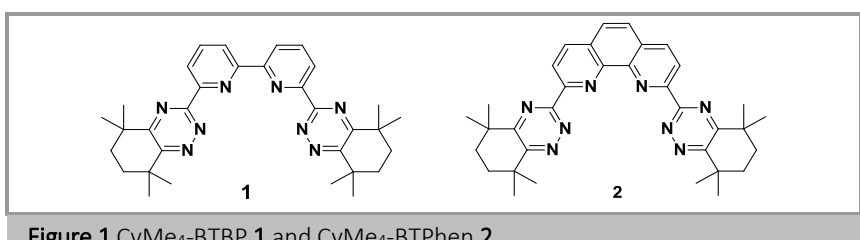

Figure $1 \mathrm{CyMe}_{4}-\mathrm{BTBP} 1$ and $\mathrm{CyMe}_{4}-\mathrm{BTPhen} 2$.

Previous work on the minor actinide-lanthanide separations has focused on solvent extraction processes (e.g. SANEX process) but these processes come with other disadvantages, such as the requirement for substantial liquid storage and containment and generation of additional secondary waste. ${ }^{22,23}$ Although much progress has been made concerning the development of extractants for the liquid-liquid extraction processes that can partition minor actinides from lanthanides, far less effort has been emphasized on the alternative approaches such as e.g. solid-liquid extraction. Replacing the current liquid-liquid extraction methods with a system based on a solid phase extractant could eliminate the large volumes of secondary organic waste generated during separation. ${ }^{24-29}$ To overcome the limitations of liquid-liquid extraction process, we previously demonstrated that when magnetic nanoparticles (MNPs) are combined with ligands such as CyMe4-BTPhen 2, these functionalized MNPs could be used to extract the minor actinides and the radioactive material could then be collected magnetically in preference to centrifugation. ${ }^{30}$ In the present study, we report an alternative route for the synthesis of tetra(4-hydroxyphenyl)BTPhen $\mathbf{1 0}$ as a highly effective reagent for carrying out actinide-lanthanide separations and investigate its extraction capabilities when immobilised on MNPs.

The first challenge in this work was to develop a fast and efficient route to produce target BTPhen ligand 10.31 Until recently, all reported syntheses ${ }^{31-36}$ of BTPhen ligands and analogues have involved the benzylic oxidation of commercially 
available neocuproine $\mathbf{3}$ using stoichiometric equivalents of $\mathrm{SeO}_{2}$ which leads to the formation of enormous amounts of toxic selenium metal rendering this route unsuitable. ${ }^{37}$ In addition, the reaction to form bisaminohydrazide 8 required 6 days to go to completion. Therefore, a new synthetic route recently developed by our group in collaboration with Whitehead et. al. ${ }^{37}$ that negated the need for toxic selenium dioxide, was adapted to our needs (Scheme 1).

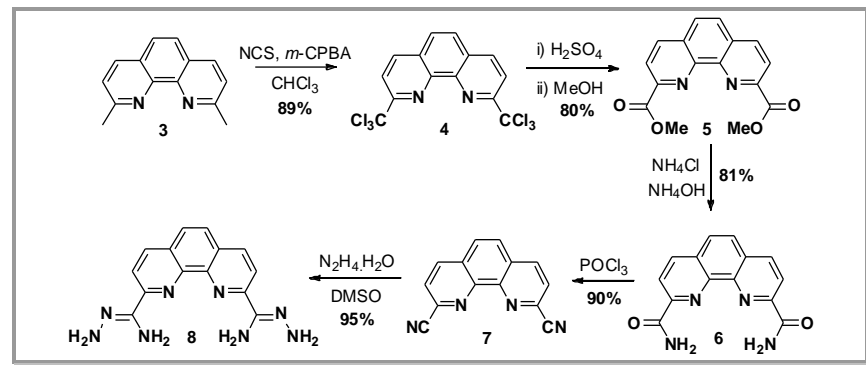

Scheme 1 Alternative route for the synthesis of bis(diaminodihydrazide) 8 .

This alternative approach (Scheme 1) to benzylic functionalization commenced with the per-chlorination of the two methyl groups of 3 using 6 equivalents of $\mathrm{N}$ chlorosuccinimide, with $m$-CPBA as initiator. ${ }^{37}$ Subsequent hydrolysis of 4 using concentrated $\mathrm{H}_{2} \mathrm{SO}_{4}$ forms a bis-acid, which is rapidly converted to di-ester $\mathbf{5}$ upon addition of methanol. The synthesis of bis-amide 6 was carried out by stirring 6 with excess ammonium chloride in concentrated $\mathrm{NH}_{4} \mathrm{OH}$ at ambient temperature over 2 days. Dehydration of 6 to di-nitrile 7 was achieved by refluxing in neat phosphorous oxychloride $\left(\mathrm{POCl}_{3}\right)$. The previous synthetic step to form the bisaminohydrazide $\mathbf{8}$ was performed by the reaction of $\mathbf{7}$ with hydrazine hydrate in EtOH and required 6 days of stirring at room temperature. We proposed that the long reaction time might be due to the poor solubility of the $\mathbf{7}$ in EtOH slowing the rate of reaction. Therefore, we changed the reaction solvent from EtOH to DMSO, which fully dissolved the dinitrile $\mathbf{7}$ and led to the reduction in reaction time from 6 days to just 3 hours.

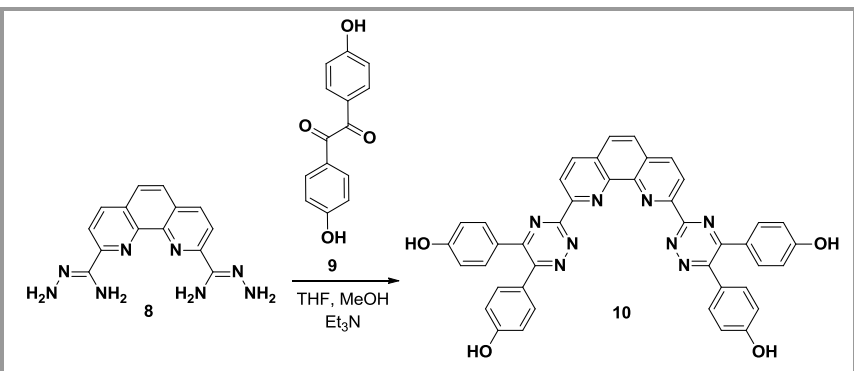

Scheme 2 Synthesis of tetra(4-hydroxyphenyl)BTPhen 10.

The tetra(4-hydroxyphenyl)BTPhen $\mathbf{1 0}$ was synthesized by our previously reported protocol as shown in Scheme 2. ${ }^{31,35}$ This tetra(4-hydroxyphenyl)-BTPhen ligand $\mathbf{1 0}$ was then immobilized onto iodoalkyl-functionalized $\mathrm{SiO}_{2}$-coated MNPs 11 prepared according to our previous work (Scheme 3). ${ }^{30}$

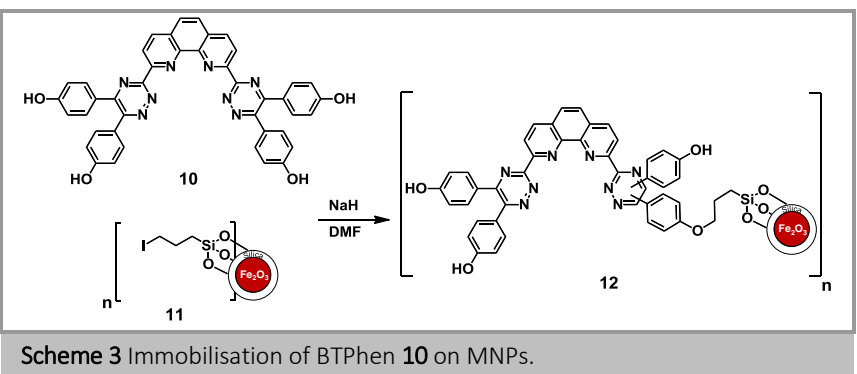

Several characterization methods were employed to assess the degree of immobilization of BTPhen ligand $\mathbf{1 0}$ onto the surface of MNPs. In the FT-IR spectra of iodoalkyl-functionalized $\mathrm{SiO}_{2}$-coated MNPs 11 and BTPhen-functionalized $\mathrm{SiO}_{2}$-coated MNPs 12, strong absorption bands centred at $1050 \mathrm{~cm}^{-1}$ owing to $\mathrm{Si}-\mathrm{O}$-Si stretching were observed for both samples. However, the absorptions at $1500-1600 \mathrm{~cm}^{-1}$ owing to $\mathrm{C}=\mathrm{C}$ aromatic vibrations were only observed for the BTPhen-functionalized $\mathrm{SiO}_{2}$-coated MNPs 12 (See supporting information).

Thermogravimetric analysis indicated that the amount of BTPhen ligand 10 bound onto the MNPs was about $c a$. 25\% (See Supporting Information). Surface morphology and structural features of BTPhen-functionalized $\mathrm{SiO}_{2}$-coated MNPs $\mathbf{1 2}$ were studied by TEM and SEM analysis (See Supporting Information). Besides the spherical core structure, a more disordered organic moiety layer could be seen in which the thickness of the outer layer was determined to be $c a .10 \mathrm{~nm}$. Furthermore, elemental analysis found a decrease in the iodine content from $38.9 \%$ in $\mathbf{1 1}$ to $1.4 \%$ in $\mathbf{1 2}$ and the presence of $0.9 \%$ nitrogen confirming the modification of MNPs with the BTPhen ligand $\mathbf{1 0}$ (See supporting information).

The extraction data are summarized in Tables 1 and 2 . Figure 2 shows the weight distribution ratios for Am(III) and $\mathrm{Eu}(\mathrm{III})\left(D_{\mathrm{wAm}}\right.$ and $\left.D_{\mathrm{wEu}}\right)$ and the separation factors for Am(III) over $\mathrm{Eu}(\mathrm{III})\left(\mathrm{SF}_{\mathrm{Am} / \mathrm{Eu}}\right)$ for BTPhen-functionalized $\mathrm{SiO}_{2}$-coated MNPs 12 as a function of nitric acid concentration $(0.001 \mathrm{M}-4$ M). The MNPs 12 exhibited high extraction ability for both $\mathrm{Am}(\mathrm{III})$ and $\mathrm{Eu}(\mathrm{III})\left(D_{\mathrm{w}}>600\right)$ at $0.001 \mathrm{M} \mathrm{HNO}_{3}$ solution with no selectivity $\left(\mathrm{SF}_{\mathrm{Am} / \mathrm{Eu}}=0.73 \pm 0.04\right)$ for Am(III) over Eu(III). At 0.1 $\mathrm{M} \mathrm{HNO}_{3}$, the $D_{\mathrm{w}}$ for $\mathrm{Am}(\mathrm{III})$ is larger than 450 indicating that an effective extraction can still be achieved at $0.1 \mathrm{M} \mathrm{HNO}_{3}$ solution. However, the $D_{\mathrm{w}}$ for Eu(III) falls from $858 \pm 24$ to $15 \pm 1$ resulting in a high $\mathrm{SF}_{\mathrm{Am} / \mathrm{Eu}}=30 \pm 2$. With increasing $\mathrm{HNO}_{3}$ concentration (1 M), decreases in the $D_{\mathrm{w}}$ values for both Am(III) and $\mathrm{Eu}(\mathrm{III})$ were observed $\left(D_{\mathrm{wAm}}=25 \pm 1, D_{\mathrm{wEu}}\right.$ was under the detection limit, i.e. $D_{\mathrm{wEu}}<3.0$ ), resulting in separation factor $\mathrm{SF}_{\mathrm{Am} / \mathrm{Eu}}>8$. At $4 \mathrm{M} \mathrm{HNO}_{3}$ a further decrease in value for Am (III) gave $D_{\mathrm{wAm}}=10 \pm 1 ; D_{\mathrm{w}}$ value observed for Eu(III) was again < 3.0 and the resulting separation factor was $\mathrm{SF}_{\mathrm{Am} / \mathrm{Eu}}>3$.

Table 1 Extraction of $\mathrm{Am}(\mathrm{III})$ and $\mathrm{Eu}(\mathrm{III})$ by BTPhen-functionalized $\mathrm{SiO}_{2-}$ coated MNPs 12 as a function of nitric acid concentration.

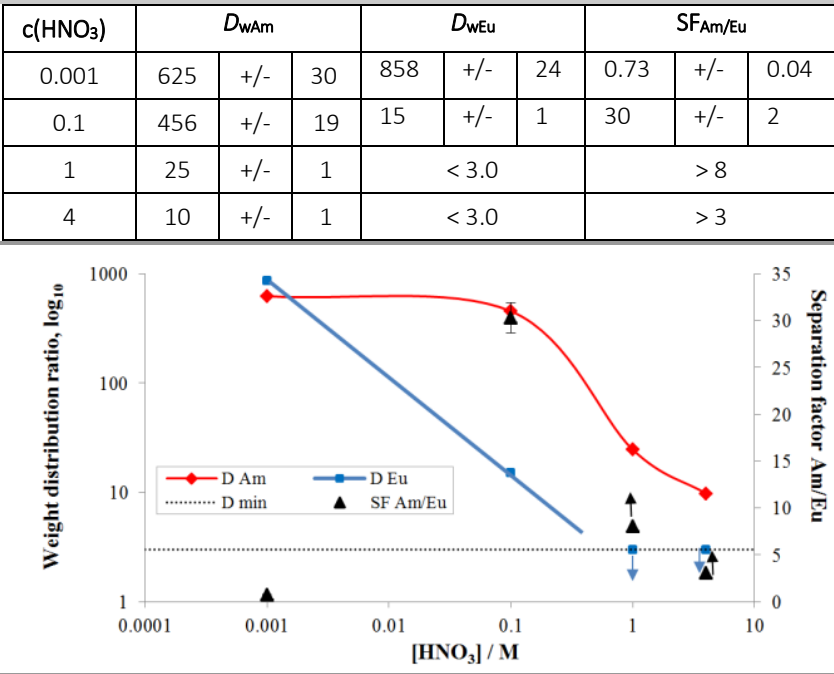

Figure 2 Extraction of $\mathrm{Am}(\mathrm{III})$ and $\mathrm{Eu}(\mathrm{III})$ by BTPhen-functionalized $\mathrm{SiO}_{2}$-coated MNPs 12 as a function of nitric acid concentration.

These results are very similar to those of our previous work where BTPhen ligand 10 immobilized on $\mathrm{SiO}_{2}$ gel extracted both minor actinides and lanthanides at low concentrations of $\mathrm{HNO}_{3}$ yet exhibited very high selectivity for minor actinides over 
lanthanides at $4 \mathrm{M} \mathrm{HNO}_{3}\left(\mathrm{SF}_{\mathrm{Am} / \mathrm{Eu}}=140\right) .{ }^{31}$ Weight distribution ratios for $\mathrm{Am}(\mathrm{III})$ and $\mathrm{Cm}(\mathrm{III})$, and the separation factors at different nitric acid concentrations were also examined (Figure 3). The $D_{\mathrm{w}}$ values for both Am(III) and Cm(III) decreased with increasing nitric acid concentration, in agreement with the earlier results, resulting in a small but significant $\mathrm{SF}_{\mathrm{Am} / \mathrm{Cm}}=3.0 \pm$ 0.5 at $0.1 \mathrm{M} \mathrm{HNO}_{3}$.

Table 2 Extraction of $\mathrm{Am}(\mathrm{III})$ and $\mathrm{Cm}(\mathrm{III})$ by BTPhen-functionalized $\mathrm{SiO}_{2-}$ coated MNPs 12 as a function of nitric acid concentration.

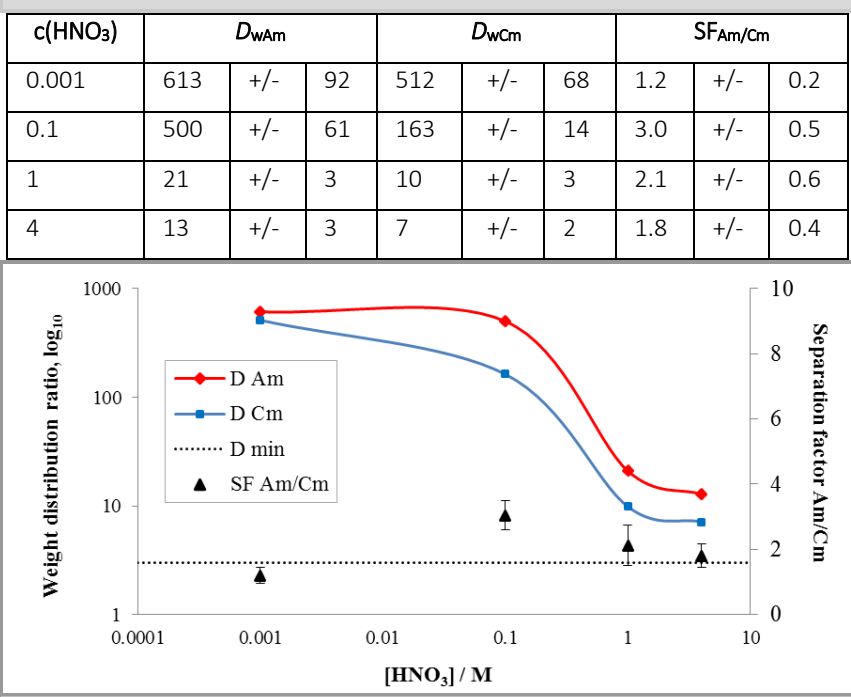

Figure 3 Extraction of $\mathrm{Am}(\mathrm{III})$ and $\mathrm{Cm}$ (III) by BTPhen-functionalized $\mathrm{SiO}_{2}$ coated MNPs 12 as a function of nitric acid concentration.

In summary, we report a modified route for synthesis of BTPhen ligand $\mathbf{1 0}$ avoiding the use of toxic $\mathrm{SeO}_{2}$ and immobilisation of BTPhen ligand $\mathbf{1 0}$ on $\mathrm{SiO}_{2}$-coated MNPs. These functionalized MNPs $\mathbf{1 2}$ exhibited good selectivity for $\mathrm{Am}(\mathrm{III})$ over $\mathrm{Eu}(\mathrm{III})$ at $0.1 \mathrm{M} \mathrm{HNO}_{3}$ (with a separation factor of 30) and showed a small but significant selectivity for Am(III) over $\mathrm{Cm}$ (III) with a nominal separation factor of around 3 in $1 \mathrm{M}$ $\mathrm{HNO}_{3}$. Furthermore, both $\mathrm{Am}(\mathrm{III})$ and $\mathrm{Eu}(\mathrm{III})$ can be coextracted at low concentrations of $\mathrm{HNO}_{3}(0.001 \mathrm{M})$ if required. The uptake behavior of Am(III) and Eu(III) by MNPs 12 at different molarities of $\mathrm{HNO}_{3}$ demonstrates that the extraction process is highly dependent on $\mathrm{HNO}_{3}$ concentration and these results represent a substantial breakthrough in the development of solid-phase materials for the important and challenging minor actinide-lanthanide separation.

\section{Funding Information}

The authors acknowledge the UK Engineering and Physical Sciences Research Council (grant No. EP/M026485/1) and the Grant Agency of the Czech Technical University in Prague (grant No. SGS15/216/OHK4/3T/14) for financial support (A.A. and P.D., respectively).

\section{Acknowledgment}

Use of the Chemical Analysis Facility (CAF) and Electron Microscopy Laboratory (EMLab) at the University of Reading is gratefully acknowledged. We also would like to thank Dr Peter Harris and Miss Amanpreet Kaur for their assistance with TEM and SEM measurements, respectively.

\section{Supporting Information}

YES (this text will be updated with links prior to publication)

\section{Primary Data}

NO (this text will be deleted prior to publication)

\section{References and Notes}

(1) Kolarik, Z. Chem. Rev. 2008, 108 (10), 4208-4252.

(2) Panak, P. J.; Geist, A. Chem. Rev. 2013, 113 (2), 1199-1236.

(3) Veliscek-Carolan, J. J. Hazard. Mater. 2016, 318, 266-281.

(4) Hudson, M. J.; Harwood, L. M.; Laventine, D. M.; Lewis, F. W. Inorg. Chem. 2013, 52 (7), 3414-3428.

(5) Sood, D. D.; Patil, S. K. J. Radioanal. Nucl. Chem. 1996, 203 (2), 547573.

(6) Bisson, J.; Dehaudt, J.; Charbonnel, M.-C.; Guillaneux, D.; Miguirditchian, M.; Marie, C.; Boubals, N.; Dutech, G.; Pipelier, M.; Blot, V.; et al. Chem. Eur. J. 2014, 20 (25), 7819-7829.

(7) Jensen, M. P.; Chiarizia, R.; Ulicki, J. S.; Spindler, B. D.; Murphy, D. J.; Hossain, M. M.; Roca-Sabio, A.; de Blas, A.; Rodríguez-Blas, T. Solvent Extr. Ion Exch. 2015, 33 (4), 329-345.

(8) Xu, L.; Zhang, A.; Lu, Y.; Yang, H.; Liu, Z. RSC Adv. 2016, 6 (102), 99859-99866.

(9) Xiao, C.-L.; Wang, C.-Z.; Mei, L.; Zhang, X.-R.; Wall, N.; Zhao, Y.-L.; Chai, Z.-F.; Shi, W.-Q. Dalt. Trans. 2015, 44 (32), 14376-14387.

(10) Huang, Q.-R.; Kingham, J. R.; Kaltsoyannis, N. Dalt. Trans. 2015, 44 (6), 2554-2566.

(11) Zhang, A.; Xu, L.; Lei, G. New J. Chem. 2016, 40 (7), 6374-6383.

(12) Whittaker, D. M.; Griffiths, T. L.; Helliwell, M.; Swinburne, A. N.; Natrajan, L. S.; Lewis, F. W.; Harwood, L. M.; Parry, S. A.; Sharrad, C. A. Inorg. Chem. 2013, 52 (7), 3429-3444.

(13) Coogan, N. T.; Chimes, M. A.; Raftery, J.; Mocilac, P.; Denecke, M. A. J. Org. Chem. 2015, 80 (17), 8684-8693.

(14) Wagner, C.; Mullich, U.; Geist, A.; Panak, P. J. Dalt. Trans. 2015, 44 (39), 17143-17151.

(15) Bremer, A.; Whittaker, D. M.; Sharrad, C. A.; Geist, A.; Panak, P. J. Dalt. Trans. 2014, 43 (6), 2684-2694.

(16) Beele, B. B.; Skerencak-Frech, A.; Stein, A.; Trumm, M.; Wilden, A.; Lange, S.; Modolo, G.; Mullich, U.; Schimmelpfennig, B.; Geist, A.; et al. New J. Chem. 2016, 40 (12), 10389-10397.

(17) Afsar, A.; Distler, P.; Harwood, L. M.; John, J.; Westwood, J. J. Org. Chem. 2016, 81 (21), 10517-10520.

(18) Afsar, A.; Laventine, D. M.; Harwood, L. M.; Hudson, M. J.; Geist, A. Chem. Commun. 2013, 49 (76), 8534-8536.

(19) Magnusson, D.; Christiansen, B.; Foreman, M. R. S.; Geist, A.; Glatz, J. -P.; Malmbeck, R.; Modolo, G.; Serrano-Purroy, D.; Sorel, C. Solvent Extr. Ion Exch. 2009, 27 (2), 97-106.

(20) Lewis, F. W.; Harwood, L. M.; Hudson, M. J.; Geist, A.; Kozhevnikov, V. N.; Distler, P.; John, J. Chem. Sci. 2015, 6 (8), 4812-4821.

(21) Lewis, F. W.; Harwood, L. M.; Hudson, M. J.; Drew, M. G. B.; Wilden, A.; Sypula, M.; Modolo, G.; Vu, T.-H.; Simonin, J.-P.; Vidick, G.; et al. Procedia Chem. 2012, 7, 231-238.

(22) Kaur, M.; Zhang, H.; Martin, L.; Todd, T.; Qiang, Y. Environ. Sci. Technol. 2013, 47 (21), 11942-11959.

(23) Shusterman, J. A.; Mason, H. E.; Bowers, J.; Bruchet, A.; Uribe, E. C.; Kersting, A. B.; Nitsche, H. ACS Appl. Mater. Interfaces 2015, 7 (37), 20591-20599.

(24) Kameník, J.; Šebesta, F.; John, J.; Böhmer, V.; Rudzevich, V.; Grüner, B. J. Radioanal. Nucl. Chem. 2015, 304 (1), 313-319.

(25) Liu, R.; Wei, Y.; Xu, Y.; Usuda, S.; Kim, S.; Yamazaki, H.; Ishii, K. J. Radioanal. Nucl. Chem. 2012, 292 (2), 537-544.

(26) Ning, S.; Zou, Q.; Wang, X.; Liu, R.; Wei, Y.; Zhao, Y.; Ding, Y. J. 
Radioanal. Nucl. Chem. 2016, 307 (2), 993-999.

(27) Higginson, M. A.; Marsden, O. J.; Thompson, P.; Livens, F. R.; Heath, S. L. React. Funct. Polym. 2015, 91-92, 93-99.

(28) Veliscek-Carolan, J.; Jolliffe, K. A.; Hanley, T. L. Chem. Commun. 2015, 51 (57), 11433-11436.

(29) Chen, X. T.; He, L. F.; Liu, R. Z.; Zhang, C.; Liu, B.; Tang, Y. P. RSC Adv. 2015, 5 (70), 56658-56665.

(30) Afsar, A.; Harwood, L. M.; Hudson, M. J.; Distler, P.; John, J. Chem. Commun. 2014, 50 (95), 15082-15085.

(31) Afsar, A.; Distler, P.; Harwood, L. M.; John, J.; Westwood, J. Chem. Commun. 2017, 53 (28), 4010-4013.

(32) Laventine, D. M.; Afsar, A.; Hudson, M. J.; Harwood, L. M.
Heterocycles 2012, 86 (2), 1419-1429.

(33) Higginson, M. A.; Kyle, N. D.; Marsden, O. J.; Thompson, P.; Livens, F. R.; Heath, S. L. Dalt. Trans. 2015, 44 (37), 16547-16552.

(34) Wu, H.; Wu, Q.-Y.; Wang, C.-Z.; Lan, J.-H.; Liu, Z.-R.; Chai, Z.-F.; Shi, W.-Q. Dalt. Trans. 2016, 45 (19), 8107-8117.

(35) Tai, S.; Williams, N. J.; Carrick, J. D. J. Heterocycl. Chem. 2016, 53 (1), 307-312.

(36) Williams, N. J.; Dehaudt, J.; Bryantsev, V. S.; Luo, H.; Abney, C. W.; Dai, S. Chem. Commun. 2017, 53 (18), 2744-2747.

(37) Edwards, A. C.; Wagner, C.; Geist, A.; Burton, N. A.; Sharrad, C. A.; Adams, R. W.; Pritchard, R. G.; Panak, P. J.; Whitehead, R. C.; Harwood, L. M. Dalt. Trans. 2016, 45 (45), 18102-18112. 